\title{
Impact of Vitamin C intake on the Quality of Life in Head and Neck Cancer Patients of North India
}

\author{
Manjulika Gautam* ${ }^{1}$, Prof. Udai Pratap Singh ${ }^{2}$, Dr. Rohini Khurana ${ }^{3}$, Anju Pandey ${ }^{4}$ \\ ${ }^{I}$ Ph. D. Research Scholar at Department of Anthropology, University of Lucknow \\ ${ }^{2}$ Professors, Department of Anthropology, University of Lucknow \\ ${ }^{3}$ Professor, Department of Radiation Oncology, Dr RMLIMS, Lucknow \\ ${ }^{4}$ Dietician, Cancer Support Group, Department of Radiation Oncology, Dr RMLIMS, Lucknow
}

\begin{abstract}
Alternative medicines are most sought after directions when the patients are diagnosed with high grade carcinomas. The rise in the use of dietary supplements and herbal medications by patients makes it imperative to re-evaluate the past findings of clinical studies. Among unconventional approaches, high dose vitamin $\mathrm{C}$ is one of the most widely used and studied, yet controversial approaches. In case of the high-symptom burden and high morbidity, evaluation of quality of life (QOL) becomes important. The study therefore evaluates the impact of intake of $120 \mathrm{mg} / \mathrm{day}$ vitamin $\mathrm{C}$ from natural sources on quality of life of head and neck cancer patients $(\mathrm{N}=20)$ at a tertiary care centre located in Lucknow. The responses were obtained using the bilingual EORTC QLQ-C30 (version3.0) and EORTC QLQ-HN35 (version 1.0). The results obtained from dependent sample t-test reveal that oral intake of vitamin $\mathrm{C}$ from natural sources can be helpful in providing relief from constipation and problems related to teeth. The study suggests that the oral intake can be helpful in mitigation of cancer and further research should be done as to determine the further applicability of vitamin $\mathrm{C}$ in treatment of cancer.
\end{abstract}

Keywords - Natural vitamin C intake, Head and neck cancer, Quality of life, EORTC QLQ

\section{Introduction}

The complementary and alternative medicines are the most sought after directions when the patients are diagnosed with high grade carcinomas. These medicines may include herbal teas, plant extracts, vitamin s, high dose antioxidants, and mind body techniques. The rise in the use of dietary supplements and herbal medications by patients makes it imperative to re-evaluate the past findings of clinical studies. Among unconventional approaches, high dose vitamin $\mathrm{C}$ is one of the most widely used and studied, yet controversial approaches. (Park, 2013) (Ohno, Chno, Suzuki, Soma, \& Inoue, 2009) Vitamin C is a water soluble glucose derivative with antioxidant activity in vitro and in vivo. It functions as an essential co factor for various enzymes in diverse metabolic pathways and exerts many non enzymatic actions, including antioxidant effects. Antioxidant supplements (Beta Carotene and vitamin C) increase the resistance of lymphocytes to oxidative damage. (Dua, Cullena, \& Buethnera, 2012).Recent evidences indicates that an increased intake of vitamin $\mathrm{C}$ is associated with a reduced risk of chronic diseases such as cancer, cardiovascular diseases, cataracts and other eye diseases, and neurodegenerative conditions probably through antioxidant mechanisms.

\section{Quality of Life Assessment}

In View of the severe symptom and high morbidity, the evaluation of quality of life (QOL) becomes significant.
Quality of life assessments also help in comparing different therapeutic regimes, thus allowing selection of the acceptable modality. Problems of inconsistent interpretability and high-patient dropout rate pose a challenging problem that must be tackled. In spite of those drawbacks, QOL is now considered to be an important component of carcinoma management and will be performed routinely. This practice helps the physician to plan suitable treatment strategies and fix practical therapeutic goals. Measuring QOL is especially useful for drawing definite conclusions regarding the efficacy of a particular therapeutic regimen. Quality of life assessments should be given due priority whenever it is expected that the survival differences between the treatment groups is going to be small (a frequent occurrence), or when the difference in at least one factor predicting QOL is expected to be large.

The effect of two different therapeutic modalities on QOL and overall survival helps select the better modality. In fact, a particular treatment may be preferred if it improves the QOL even if the survival is not superior to the other. On the other hand, a treatment may be unsatisfactory and may be rejected if the QOL remains similar or worsens compared to another modality, without offering any survival advantage. However, two situations present difficulty: one, if the treatment improves QOL but deteriorates survival, and in second, QOL worses but survival improves. In these situations, the choice of treatment is usually made jointly by the physician and the patient after detailed consideration of all relevant aspects. The study aimed to fulfill following objectives: 
- To describe socio-demographic characteristics of the sample population

- To determine the minimum possible intake of Vitamin C by cancer patients.

- To examine the impact of Vitamin $\mathrm{C}$ on the quality of life of oral cancer patients.

- To establish the need of Vitamin C intake by cancer patients.

\section{Methodology}

The study was cross sectional, qualitative, prospective and quasi experimental. The study was conducted at Radiation Oncology department of a tertiary care center situated in Lucknow. Vitamin C dosage i.e. $100-120 \mathrm{mg} / \mathrm{d}$ will be given to the patients for duration of 1 and half months when they will be receiving radiotherapy or chemotherapy at the facility.

\section{Study Design}

Study Area: The Universe of data included all the patients coming to the facility for treatment (both Radiation and Chemotherapy) of a pre diagnosed Carcinoma for a minimum period of 2 months.

Sampling: Purposive sampling was applied to select the respondents. Selection criteria for the respondents was patients with pre diagnosed Carcinoma of Head and Neck, varying in disease stage and treatment modality, who give their consent for the purpose of the study.

Data Collection: The consent and demographic data of the patients $(\mathrm{N}=20)$ was collected prior to the study. Data was collected through semi structured interviews, EORTC QLQ-C30 (Version 3.0) questionnaire (Aaronson NK, 1993) twice i.e. before and after the intervention is given.

- Step1- The patients were given the EORTC QLQ-C30 questionnaire which they have to fill and submit on the spot during their visit to the Cancer Support Group or during day care for the chemotherapy at Dr.RMLIMS, Lucknow.

- Step 2- During the same session the patients were told about the Vitamin $\mathrm{C}$ intake. They were given a list of natural Vitamin $\mathrm{C}$ supplements i.e. fruits and vegetables available during the season such that they intake at least $120 \mathrm{mg} /$ day.

- Step 3- They were administered the questionnaire again after a month.

Data Analysis: The data of semi structured interviews were recorded and treated qualitatively. The EORTC QLQC30 (Version 3.0) questionnaire along with EORTC QLQHN35 questionnaire (Version 1.0) (Aaronson NK A. S., 1993) data was treated quantitatively and scoring and analysis was done manually based on the EORTC scoring manual (Fayers PM, 2001).

\section{Results}

The study produced the following results. The demographic data of the patients, varying in disease stage and treatment modality (i.e. surgery, radiotherapy and chemotherapy), is taken as their age and gender.

\subsection{Demographic Data}

- Age: The age groups of the participants $(\mathrm{N}=20)$ during the study are presented in the table below.

Table 1: Age of the participants

\begin{tabular}{|l|l|l|}
\hline AGE & N & \% \\
\hline$<40$ & 4 & 20 \\
\hline $40-49$ & 5 & 25 \\
\hline $50-59$ & 4 & 20 \\
\hline $60-69$ & 6 & 30 \\
\hline $70-79$ & 0 & 0 \\
\hline $80+$ & 1 & 5 \\
\hline Total & 20 & 100 \\
\hline
\end{tabular}

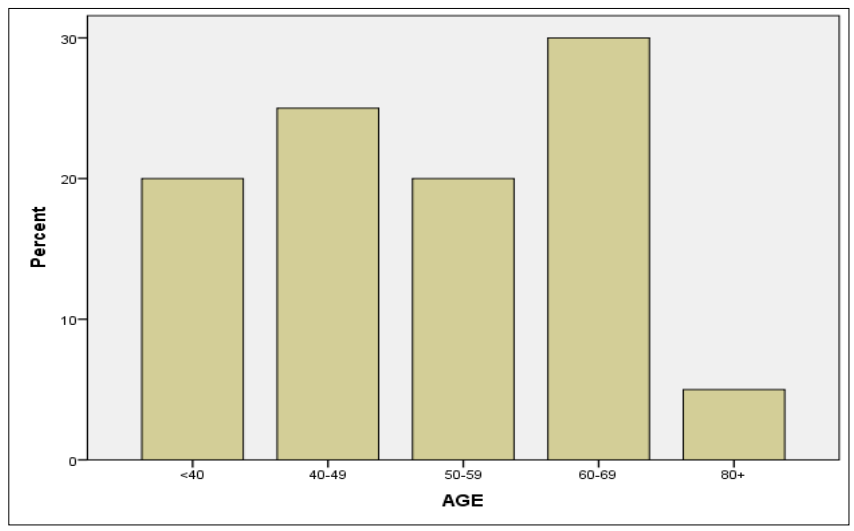

Fig. 1: Age groups of the participants.

The figure shows that the maximum number of patients belonged to the age group 60-69 years (30\%), followed by age group 40-49 years (25\%). 20\% patients belonged to age groups $<40$ years and 50-59 years each. Least frequent group was reported to be $80+$ years while none of the patients belonged to the age group 70-79 years.

- Gender: The study included $90 \%$ males and $10 \%$ females.(Table 2)

Table 2: Gender of the participants

\begin{tabular}{|l|l|l|}
\hline GENDER & $\mathbf{N}$ & \% \\
\hline Male & 18 & 90 \\
\hline Female & 2 & 10 \\
\hline Total & 100 & 100 \\
\hline
\end{tabular}




\section{Data from EORTC QLQ-C30 (Version 3.0)}

The following results are presented on the basis of the scores of the participants obtained in EORTC QLQ-C30 (Version 3.0) administered along with EORTC QLQ-HN35 before and after the implementation of the Vitamin $\mathrm{C}$ intake in the diet. A high score for a functional scale represents a high / healthy level of functioning; A high score for the global health status / QoL represents high
QoL, but a high score for a symptom scale / item represents a high level of symptomatology / problems.

Constructed scales: Table 3 presents the mean, standard deviation, median and Inter quartile range (IQR) of the scales obtained from the raw scores obtained by the patients in EORTC QLQ-C30 (Version3.0). The constructed scales covered by the questionnaire reflect the multi-dimensionality of the QL construct.

Table 3: The descriptive statistics of the scales

\begin{tabular}{|c|c|c|c|c|c|c|c|c|c|}
\hline \multirow{2}{*}{ Constructed scales } & & \multicolumn{2}{|l|}{ Mean } & \multicolumn{2}{|l|}{ SD } & \multicolumn{2}{|l|}{ Median } & \multicolumn{2}{|l|}{$\mathrm{IQR}$} \\
\hline & & Before & After & Before & After & Before & After & Before & After \\
\hline Global health status/QL & QL & 30 & 20.00 & 25.13 & 29.91 & 50 & 0 & $0-50$ & $0-100$ \\
\hline \multicolumn{10}{|l|}{ Function Scales } \\
\hline Physical functioning & $\mathrm{PF}$ & 76.34 & 78.66 & 11.55 & 11.97 & 80 & 80 & $53.3-93.3$ & $53.3-100$ \\
\hline Role Functioning & RF & 76.67 & 70.01 & 14.69 & 14.90 & 83.3 & 66.7 & $50-100$ & $33.3-100$ \\
\hline Emotional functioning & $\mathrm{EF}$ & 78.76 & 77.09 & 14.17 & 9.70 & 83.3 & 75 & $41.7-100$ & $58.3-91.7$ \\
\hline Cognitive functioning & $\mathrm{CF}$ & 78.33 & 80.00 & 19.57 & 14.89 & 83.3 & 83.3 & $33.3-100$ & $50-100$ \\
\hline Social functioning & SF & 78.34 & 77.50 & 20.30 & 17.33 & 83.3 & 83.3 & $33.3-101$ & $33.3-100$ \\
\hline \multicolumn{10}{|l|}{ Symptom Scales } \\
\hline Fatigue & FA & 26.65 & 22.76 & 14.14 & 18.19 & 22.2 & 22.2 & $0-55.6$ & $0-77.8$ \\
\hline Nausea and vomiting & $\mathrm{NV}$ & 18.35 & 23.34 & 16.13 & 16.57 & 16.7 & 16.7 & $0-66.7$ & $0-50$ \\
\hline Pain & PA & 18.34 & 23.34 & 11.95 & 18.25 & 16.7 & 16.7 & $0-33.3$ & $0-66.7$ \\
\hline Dyspnoea & DY & 23.33 & 23.33 & 26.72 & 24.43 & 16.65 & 33.3 & $0-66.7$ & $0-66.8$ \\
\hline Insomnia & SL & 36.66 & 36.66 & 21.37 & 23.96 & 33.3 & 33.3 & $0-66.7$ & $0-66.9$ \\
\hline Appetite loss & AP & 33.31 & 29.98 & 32.44 & 23.94 & 33.3 & 33.3 & $0-133.3$ & $0-100$ \\
\hline Constipation & $\mathrm{CO}$ & 34.99 & 18.32 & 27.53 & 17.00 & 33.3 & 33.3 & $0-100$ & $0-33.3$ \\
\hline Diarrhoea & DI & 21.65 & 23.32 & 19.56 & 21.90 & 33.3 & 33.3 & $0-66.7$ & $0-66.7$ \\
\hline Financial difficulties & FI & 16.65 & 18.32 & 17.08 & 17.00 & 16.65 & 33.3 & $0-33.3$ & $0-33.3$ \\
\hline
\end{tabular}

The scores related to various scales suggest that the mean scores have increased after the Vitamin $C$ intervention. Median scores have shifted only in QL, RF, EF, DY, and FI scales.

- Global Health Status / QL - Quality of life or the global health status is the overall summary measure.

Table 4: Change in health status (QL)

\begin{tabular}{|l|l|l|}
\hline QL & Before & After \\
\hline 0 & 40 & 65 \\
\hline 50 & 60 & 30 \\
\hline 100 & 0 & 5 \\
\hline Total & 100 & 100 \\
\hline
\end{tabular}

A high score in QoL mean better global health status. From the table above (Table 4) the health status of $25 \%$ participants declined while $5 \%$ improved their health status.

- Functional Scale - Physical Functioning: Physical functioning of patients having score 53.3 declined by $5 \%$ after the Vitamin C intervention. 5\% patients got their physical functioning improved up to score 100 after the intervention (Table 5).
Table 5: Change in physical functioning (PF)

\begin{tabular}{|l|l|l|}
\hline PF & Before & After \\
\hline 53.3 & 10 & 5 \\
\hline 60.0 & 5 & 5 \\
\hline 66.7 & 10 & 10 \\
\hline 73.3 & 20 & 25 \\
\hline 80.0 & 20 & 20 \\
\hline 86.7 & 30 & 15 \\
\hline 93.3 & 5 & 15 \\
\hline 100 & 0 & 5 \\
\hline Total & 100 & 100 \\
\hline
\end{tabular}

- Role Functioning - 10\% of those (having 100 score) who could do their daily chores and work earlier were not able to do so after the intervention. Although the percentage of those has scored 66.7 increased to $50 \%$ still none of the earlier low scorers could make to this group (Table 6).

Table 6: Change in role functioning ( $R F)$

\begin{tabular}{|l|l|l|}
\hline RF & Before & After \\
\hline 33.30 & 0 & 5 \\
\hline 50.0 & 10 & 10 \\
\hline 66.7 & 35 & 50 \\
\hline 83.3 & 40 & 30 \\
\hline 100.0 & 15 & 5 \\
\hline Total & 100 & 100 \\
\hline
\end{tabular}


- Emotional Functioning - Table 7 shows the change in scores of patients in terms of their emotional functioning viz- a measure of tension, worry, irritation and depression.

Table 7: Change in emotional functioning (EF)

\begin{tabular}{|l|l|l|}
\hline EF & Before & After \\
\hline 41.7 & 5 & 0 \\
\hline 58.3 & 5 & 5 \\
\hline 66.7 & 20 & 25 \\
\hline 75.0 & 10 & 25 \\
\hline 83.3 & 30 & 30 \\
\hline 91.7 & 25 & 15 \\
\hline 100.0 & 5 & 0 \\
\hline Total & 100 & 100 \\
\hline
\end{tabular}

A decline is seen among those having good emotional functioning, at score 100 , by $5 \%$. Those having low score in emotional functioning are also declined by $5 \%$. Participants having 75 score increased by $15 \%$ after the intervention.

- Cognitive Functioning: Cognitive functioning at score 100 was observed among $25 \%$ patients as compared to $30 \%$ prior to the intervention. $35 \%$ patients reported their cognitive functioning at a score of 83.3 after the intervention.

Table 8: Change in cognitive functioning (CF)

\begin{tabular}{|l|l|l|}
\hline CF & Before & After \\
\hline 33.3 & 5 & 0 \\
\hline 50.0 & 10 & 5 \\
\hline 66.7 & 25 & 35 \\
\hline 83.3 & 30 & 35 \\
\hline 100.0 & 30 & 25 \\
\hline Total & 100 & 100 \\
\hline
\end{tabular}

- Social Functioning - Family life and participation in social activities included in the social functioning scale was recorded to have had improved among 5\% participants and declined among 5\% patients. (Table 9)

Table 9: Change in social functioning (SF)

\begin{tabular}{|l|l|l|}
\hline SF & Before & After \\
\hline 33.3 & 5 & 5 \\
\hline 50.0 & 10 & 5 \\
\hline 66.7 & 30 & 30 \\
\hline 83.3 & 20 & 40 \\
\hline 100.0 & 35 & 20 \\
\hline Total & 100 & 100 \\
\hline
\end{tabular}

\subsection{Symptom Scale}

- Fatigue: Fatigue as the symptomatic expression was experienced more by 5\% participants, as score 100, after the intervention. The lowest score, 0, implying least fatigue was recorded by $10 \%$ participants after the intervention. (Table 10).

Table 10: Change in experiencing fatigue (FA)

\begin{tabular}{|l|l|l|}
\hline FA & Before & After \\
\hline 0 & 5 & 10 \\
\hline 11.1 & 20 & 35 \\
\hline 22.2 & 30 & 25 \\
\hline 33.3 & 25 & 15 \\
\hline 44.4 & 15 & 10 \\
\hline 55.6 & 5 & 0 \\
\hline 77.8 & 0 & 5 \\
\hline Total & 100 & 100 \\
\hline
\end{tabular}

- Nausea and Vomiting: Those having a high score in nausea and vomiting experienced relief and none of the patients got the highest score (66.7), recorded earlier. (Table 11)

Table 11: Change in experiencing nausea and vomiting (NV)

\begin{tabular}{|l|l|l|}
\hline NV & Before & After \\
\hline 0 & 25 & 20 \\
\hline 16.7 & 50 & 35 \\
\hline 33.3 & 20 & 30 \\
\hline 50 & 0 & 15 \\
\hline 66.7 & 5 & 0 \\
\hline Total & 100 & 100 \\
\hline
\end{tabular}

- Pain: Change in experiencing pain is presented in Table 12. Those having score 0 remained the same while those having score $16.7,33.3$ declined by $10 \%$ and $5 \%$ respectively. $15 \%$ patients experienced more pain than before and score 50 was obtained by $10 \%$, and score 66.7 was obtained by $5 \%$ of such participants.

Table 12: Change in experiencing pain (PA)

\begin{tabular}{|l|l|l|}
\hline PA & Before & After \\
\hline 0 & 20 & 20 \\
\hline 16.7 & 50 & 40 \\
\hline 33.3 & 30 & 25 \\
\hline 50.0 & 0 & 10 \\
\hline 66.7 & 0 & 5 \\
\hline Total & 100 & 100 \\
\hline
\end{tabular}

Single Items: Table 13 presents the percentages of responses to single item based questions of the questionnaire. 
Table 13: Item-wise changes in responses

\begin{tabular}{|c|c|c|c|c|c|c|c|c|c|c|c|c|c|c|c|c|}
\hline \multirow[t]{2}{*}{ No. } & \multirow{2}{*}{ Single Items } & \multirow{2}{*}{ Scale } & \multicolumn{3}{|c|}{ Not at all } & & \multicolumn{3}{|c|}{ A little } & \multicolumn{4}{|c|}{ Quite a bit } & \multicolumn{3}{|c|}{ Very much } \\
\hline & & & \multicolumn{2}{|c|}{ Bef. } & Aft. & \multicolumn{2}{|r|}{ Bef. } & \multicolumn{2}{|r|}{ Aft. } & \multicolumn{2}{|c|}{ Bef. } & \multicolumn{2}{|l|}{ Aft. } & Bef. & \multicolumn{2}{|c|}{ Aft. } \\
\hline 1 & Strenuous activities & $\mathrm{PF}$ & \multicolumn{2}{|l|}{40} & 45 & \multicolumn{2}{|r|}{55} & \multicolumn{2}{|r|}{45} & \multicolumn{2}{|l|}{5} & \multicolumn{2}{|l|}{10} & 0 & \multicolumn{2}{|c|}{0} \\
\hline 2 & Long walk & $\mathrm{PF}$ & \multicolumn{2}{|l|}{25} & 50 & \multicolumn{2}{|r|}{65} & & 40 & 10 & & 10 & & 0 & 0 & \\
\hline 3 & Short walk & PF & 40 & & 45 & & 60 & & 45 & 0 & & 10 & & 0 & 0 & \\
\hline 4 & Bed or chair & $\mathrm{PF}$ & 50 & & 50 & & 30 & & 35 & 20 & & 15 & & 0 & 0 & \\
\hline 5 & Self care & PF & 40 & & 40 & & 45 & & 55 & 15 & & 5 & & 0 & 0 & \\
\hline 6 & Limited in work & $\mathrm{RF}$ & 45 & & 30 & & 50 & & 60 & 5 & & 10 & & 0 & 0 & \\
\hline 7 & Limited in leisure & RF & 35 & & 15 & & 55 & & 70 & 5 & & 15 & & 5 & 0 & \\
\hline 8 & Dyspnoea & DY & 50 & & 45 & & 30 & & 40 & 20 & & 15 & & 0 & 0 & \\
\hline 9 & Pain & PA & 50 & & 35 & & 50 & & 50 & 0 & & 15 & & 0 & 0 & \\
\hline 10 & Need to rest & FA & 40 & & 30 & & 55 & & 55 & 5 & & 10 & & 0 & 5 & \\
\hline 11 & Insomnia & SL & 15 & & 20 & & 60 & & 50 & 25 & & 30 & & 0 & 0 & \\
\hline 12 & Felt weak & FA & 25 & & 60 & & 55 & & 35 & 10 & & 5 & & 10 & 0 & \\
\hline 13 & Appetite loss & $\mathrm{AP}$ & 25 & & 25 & & 66 & & 65 & 5 & & 5 & & 0 & 5 & \\
\hline 14 & Nausea & NV & 55 & & 35 & & 40 & & 50 & 5 & & 15 & & 0 & 0 & \\
\hline 15 & Vomiting & $\mathrm{NV}$ & 45 & & 45 & & 50 & & 50 & 5 & & 5 & & 0 & 0 & \\
\hline 16 & Constipation & $\mathrm{CO}$ & 25 & & 45 & & 50 & & 55 & 20 & & 0 & & 5 & 0 & \\
\hline 17 & Diarrhoea & DI & 40 & & 40 & & 55 & & 50 & 5 & & 10 & & 0 & 0 & \\
\hline 18 & Felt tired & FA & 40 & & 50 & & 50 & & 35 & 10 & & 10 & & 0 & 5 & \\
\hline 19 & Pain interference & PA & 40 & & 50 & & 60 & & 40 & 0 & & 10 & & 0 & 0 & \\
\hline 20 & Concentration & $\mathrm{CF}$ & 50 & & 50 & & 30 & & 45 & 20 & & 5 & & 0 & 0 & \\
\hline 21 & Tension & EF & 50 & & 40 & & 45 & & 55 & 5 & & 5 & & 0 & 0 & \\
\hline 22 & Worry & EF & 40 & & 50 & & 50 & & 45 & 10 & & 5 & & 0 & 0 & \\
\hline 23 & Irritability & EF & 50 & & 45 & & 40 & & 50 & 5 & & 5 & & 5 & 0 & \\
\hline 24 & Depression & EF & 40 & & 20 & & 55 & & 65 & 5 & & 15 & & 0 & 0 & \\
\hline 25 & Memory trouble & $\mathrm{CF}$ & 55 & & 40 & & 30 & & 55 & 15 & & 5 & & 0 & 0 & \\
\hline 26 & Family life & SF & 40 & & 55 & & 60 & & 35 & 0 & & 10 & & 0 & 0 & \\
\hline 27 & Social activities & SF & 50 & & 35 & & 35 & & 50 & 10 & & 15 & & 5 & 0 & \\
\hline 28 & Financial difficulties & FI & 50 & & 45 & & 50 & & 55 & 0 & & 0 & & 0 & 0 & \\
\hline & & & 1 & & 2 & & 3 & & 4 & & 5 & & 6 & & 7 & \\
\hline & & & (ver & poor & & & & & & xcelle & & & & & & \\
\hline & & & $\mathrm{B}$ & $\mathrm{A}$ & $\mathrm{B}$ & $\mathrm{A}$ & $\mathrm{B}$ & $\mathrm{A}$ & $\mathrm{B}$ & $\mathrm{A}$ & $\mathrm{B}$ & $\mathrm{A}$ & $\mathrm{B}$ & $\mathrm{A}$ & $\mathrm{B}$ & $\mathrm{A}$ \\
\hline 29 & Overall health & QL & 60 & 75 & 0 & 0 & 0 & 0 & 0 & 0 & 0 & 0 & 0 & 0 & 40 & 25 \\
\hline 30 & Overall quality of life & QL & 80 & 85 & 0 & 0 & 0 & 0 & 0 & 0 & 0 & 0 & 0 & 0 & 20 & 15 \\
\hline
\end{tabular}

Strenuous activities increased discomfort among 5\% patients after the intervention. Long walk was easier for $25 \%$ patients after the intervention. Taking a short walk around the house was less troublesome to $5 \%$, while $10 \%$ patients had quite a bit trouble in walking around. 5\% patient who earlier spent quite a bit time lying in bed or chair felt a decrease to a little. 55\% participants needed help with eating, dressing, washing themselves or using the toilet after the intervention. $60 \%$ patients reported to be a little limited in work while $30 \%$ were not at all limited in work. $70 \%$ patients found themselves to be limited in continuing their hobbies, or simple activities of leisure. $40 \%$ patients were a little, short of breath as compared to $30 \%$ earlier. An increase towards quite a bit is observed in context of experiencing pain after the intervention. 5\% patients needed to rest much often than before while $10 \%$ needed to rest quite a bit. Those having not at all trouble in sleeping increased from 15 to $20 \%$ while those having quite a bit trouble in sleeping also increased from 25 to $30 \%$. $60 \%$ of the patients didn't felt weak after the intervention and none of them reported incidences of extreme weakness. 5\% patients reported very much appetite loss after the intervention. 15\% reported nausea as 'quite a bit' after the intervention. No change in response to the question on vomiting was found. Condition of constipation improved after the intervention among 20\% participants. 5\% more patient responded 'quite a bit' to the question on diarrhoea. 50\% patients did not felt tired after the intervention. Pain could not interfere with the daily activities among 50\% patients after the intervention. Problems in concentration were reported by $5 \%$ patients as quite a bit against $20 \%$ patients prior to the intervention. Tension increased among all the respondents after the intervention. Incidence of worrying are decreased among $10 \%$ respondents after the intervention. Irritability increased to a little among $10 \%$ participants. Depression was reported by $15 \%$ as quite a bit and $65 \%$ as a little after the intervention. Memory trouble increased among 5\% participants and declined towards a little. Family life of 55\% patients was not disturbed by the treatment undergoing. Social activities were affected as quite a bit for $15 \%$ patients as against $10 \%$ before the intervention. 
Financial difficulties due to treatment were a little increased among 55\% patients. The overall heath and overall quality of life had been marked as being very poor as increased frequencies after the intervention.

\subsection{Head and Neck Data}

The data from EORTC QLQ-HN35 (Version 1.0) is presented in the following section.

- Pain: The change in experience of pain is presented in table 14 below.

Table 14: Change in experiencing pain (HNPA)

\begin{tabular}{|l|l|l|}
\hline \multicolumn{3}{|c|}{ HNPA } \\
\hline & Before & After \\
\hline 8.33 & 20 & 15 \\
\hline 16.67 & 25 & 25 \\
\hline 25.00 & 10 & 10 \\
\hline 33.33 & 5 & 25 \\
\hline 41.67 & 20 & 15 \\
\hline 50 & 15 & 5 \\
\hline 58.33 & 5 & 5 \\
\hline Total & 100 & 100 \\
\hline
\end{tabular}

The percentage of patients with higher scores, i.e. scores $>33.33$ (in this case), has declined after the Vitamin $\mathrm{C}$ intake was increased. This shows that Vitamin $\mathrm{C}$ intake could have helped in diminishing pain. It is also evident that percentage of patients showing lowest score (8.33) along with slightly higher scores (41.07 and 50) have contributed their shares to medium condition i.e. 33.33. This show that overall there is positive impact of Vitamin $\mathrm{C}$ intake on pain experiences of the patients .

- Swallowing: Impact of Vitamin C intake on the problems in swallowing is presented in Table 15.

Table 15: Change in swallowing problems (HNSW)

\begin{tabular}{|l|l|l|}
\hline \multicolumn{3}{|c|}{ HNSW } \\
\hline & Before & After \\
\hline 0.00 & 0 & 5 \\
\hline 8.33 & 5 & 5 \\
\hline 16.67 & 25 & 10 \\
\hline 25.00 & 15 & 20 \\
\hline 33.33 & 35 & 20 \\
\hline 41.67 & 0 & 25 \\
\hline 50.00 & 10 & 5 \\
\hline 58.33 & 5 & 5 \\
\hline 83.33 & 5 & 5 \\
\hline Total & 100 & 100 \\
\hline
\end{tabular}

No change is observed among the high scoring patients. This means that the patients with more problems in swallowing did not benefit from the Vitamin $\mathrm{C}$ intake.

\section{- Senses Problems}

Table 16: Change in senses problem (HNSE)

\begin{tabular}{|l|l|l|}
\hline \multicolumn{3}{|c|}{ HNSE } \\
\hline & Before & After \\
\hline 0.00 & 50 & 50 \\
\hline 16.67 & 35 & 10 \\
\hline 33.33 & 10 & 20 \\
\hline 50.00 & 5 & 10 \\
\hline 66.67 & 0 & 10 \\
\hline Total & 100 & 100 \\
\hline
\end{tabular}

Table 16 presents the changes reported by the patients as changes in their senses of taste and smell. The highest score was observed to be 66.67 , which indicated more problems. $50 \%$ of the patients did not have problem in their eating and smelling senses. But the after scores indicate that $10 \%$ patients had more problems related to these senses after the intervention.

\section{- Speech Problems}

Table 17: Change in speech problems (HNSP)

\begin{tabular}{|l|l|l|}
\hline \multicolumn{3}{|c|}{ HNSP } \\
\hline & Before & After \\
\hline 0.00 & 15 & 15 \\
\hline 11.11 & 15 & 15 \\
\hline 22.22 & 15 & 10 \\
\hline 33.33 & 25 & 15 \\
\hline 44.44 & 25 & 30 \\
\hline 55.56 & 5 & 10 \\
\hline 77.78 & 0 & 5 \\
\hline Total & 100 & 100 \\
\hline
\end{tabular}

Table 17 presents the changes in speech problems of the patients. $15 \%$ patients experienced no problems in speaking and other vocal activities. The highest score recorded before the intervention was 55.56 and after the intervention was 77.78. Percentage of respondents having scores $44.44,55.56$ and 77.76 were increased by $5 \%$ each indicating tendency towards increased problems.

\section{- Social Eating}

Table 18: Change in trouble with social eating (HNSO)

\begin{tabular}{|l|l|l|}
\hline \multicolumn{3}{|c|}{ HNSO } \\
\hline & Before & After \\
\hline 0.00 & 10 & 5 \\
\hline 8.33 & 15 & 20 \\
\hline 16.67 & 5 & 20 \\
\hline 25.00 & 40 & 20 \\
\hline 33.33 & 20 & 20 \\
\hline 50.00 & 0 & 5 \\
\hline 75.00 & 0 & 5 \\
\hline 83.33 & 5 & 0 \\
\hline 100.00 & 5 & 5 \\
\hline Total & 100 & 100 \\
\hline
\end{tabular}


Eating with or among people was also assessed in the study under the scale social eating. Responses to these queries indicated $15 \%$ increase in the percentage of those having score 16.67 (Table 18).

\section{- Social Contact}

Table 19: Change in trouble with social contact (HNSC)

\begin{tabular}{|l|l|l|}
\hline \multicolumn{3}{|c|}{ HNSC } \\
\hline & Before & After \\
\hline 0.00 & 15 & 15 \\
\hline 6.67 & 5 & 5 \\
\hline 13.33 & 5 & 25 \\
\hline 20.00 & 20 & 0 \\
\hline 26.67 & 20 & 20 \\
\hline 33.33 & 5 & 10 \\
\hline 40.00 & 5 & 0 \\
\hline 46.67 & 15 & 5 \\
\hline 53.33 & 5 & 10 \\
\hline 60.00 & 0 & 5 \\
\hline 66.67 & 5 & 5 \\
\hline Total & 100 & 100 \\
\hline & &
\end{tabular}

Change in trouble with social contact is presented in table 19. Those having low score (i.e. 0.00, and 6.67) before the intervention continued to have less trouble after the intervention, but the percentage of the respondents having score 13.33 increased after the intervention deriving its part from the scores 33.33 and 46.67 .

- Sexuality

Table 20: Change in less sexuality (HNSX)

\begin{tabular}{|l|l|l|}
\hline \multicolumn{3}{|c|}{ HNSX } \\
\hline & Before & After \\
\hline-33.33 & 5 & 0 \\
\hline 0.00 & 5 & 5 \\
\hline 16.67 & 10 & 5 \\
\hline 33.33 & 45 & 45 \\
\hline 50.00 & 10 & 15 \\
\hline 66.67 & 5 & 20 \\
\hline 83.33 & 20 & 5 \\
\hline 100.00 & 0 & 5 \\
\hline Total & 100 & 100 \\
\hline
\end{tabular}

The sexual health of the patients is examined through this scale. The percentage of those, having fewer problems regarding their sexual well being, decreased after the intervention. But at the extreme high score end those having score 83.33 decreased by $15 \%$ (Table 20 ).

- Teeth

Table 21: Change in teeth (HNTE)

\begin{tabular}{|l|l|l|}
\hline \multicolumn{3}{|c|}{ HNTE } \\
\hline & Before & After \\
\hline 0.00 & 90 & 65 \\
\hline 33.33 & 10 & 35 \\
\hline Total & 100 & 100 \\
\hline
\end{tabular}

Table 21 presents the dental structure and framework changes among the patients. The percentage of patients having higher score increased after the intervention.

\section{- Mouth Opening}

Table 22: Change in problem in opening mouth (HNOM)

\begin{tabular}{|l|l|l|}
\hline \multicolumn{3}{|c|}{ HNOM } \\
\hline & Before & After \\
\hline 0.00 & 25 & 30 \\
\hline 33.33 & 65 & 55 \\
\hline 66.67 & 5 & 15 \\
\hline 100.00 & 5 & 0 \\
\hline Total & 100 & 100 \\
\hline
\end{tabular}

The percentage of patients having problem in opening the mouth is at score 33.33, present a decrease after the intervention. While those with fewer problems increased by $5 \%$, those having higher scored decreased (Table 22).

- Dry Mouth

Table 23: Change in having dry mouth (HNDR)

\begin{tabular}{|l|l|l|}
\hline \multicolumn{3}{|c|}{ HNDR } \\
\hline & Before & After \\
\hline 0.00 & 45 & 35 \\
\hline 33.33 & 55 & 55 \\
\hline 66.67 & 0 & 10 \\
\hline Total & 100 & 100 \\
\hline
\end{tabular}

More patients reported to have dry mouth after the intervention.

- Sticky Saliva

Table 24: Change in sticky saliva (HNSS)

\begin{tabular}{|l|l|l|}
\hline \multicolumn{3}{|c|}{ HNSS } \\
\hline & Before & After \\
\hline 0.00 & 25 & 30 \\
\hline 33.33 & 45 & 50 \\
\hline 66.67 & 25 & 20 \\
\hline 100 & 5 & 0 \\
\hline Total & 100 & 100 \\
\hline
\end{tabular}

The occurrence of sticky saliva shows some decrease as the score tends to decrease after the intervention. (Table 24) (Figure12).

\section{- Coughing}

Table 25: Change in coughing (HNCO)

\begin{tabular}{|l|l|l|}
\hline \multicolumn{3}{|c|}{ HNCO } \\
\hline & Before & After \\
\hline 0.00 & 65 & 50 \\
\hline 33.33 & 30 & 5 \\
\hline 66.67 & 5 & 40 \\
\hline 100.00 & 0 & 5 \\
\hline Total & 100 & 100 \\
\hline
\end{tabular}


Coughing scored at score 100 indicates that coughing increased after the intervention. The same implies to all the scores recorded in Table 25 (Figure 13).

- Feeling Ill

Table 26: Change in feeling ill (HNFI)

\begin{tabular}{|l|l|l|}
\hline \multicolumn{3}{|c|}{ HNFI } \\
\hline & Before & After \\
\hline 0.00 & 50 & 40 \\
\hline 33.33 & 45 & 45 \\
\hline 66.67 & 5 & 15 \\
\hline Total & 100 & 100 \\
\hline
\end{tabular}

The highest score observed on the question of feeling ill was 66.67, which means that the patient felt ill more than before, after the intervention (Table 26).

- Pain Killers

Table 27: Change in use of pain killers (HNPK)

\begin{tabular}{|l|l|l|}
\hline \multicolumn{3}{|c|}{ HNPK } \\
\hline & Before & After \\
\hline 0 & 10 & 10 \\
\hline 100 & 90 & 90 \\
\hline Total & 100 & 100 \\
\hline
\end{tabular}

The use of painkillers remained unchanged after the intervention (Table 27).

\section{- Nutritional Supplements}

Table 28: Change in requirement of nutritional supplements (excluding vitamin s) (HNNU)

\begin{tabular}{|l|l|l|}
\hline \multicolumn{3}{|c|}{ HNNU } \\
\hline & Before & After \\
\hline 0 & 10 & 10 \\
\hline 100 & 90 & 90 \\
\hline Total & 100 & 100 \\
\hline
\end{tabular}

No use of nutritional supplements, other than the Vitamin $\mathrm{C}$ intervention, was reported before and after the intervention (Table 28).

\section{- Feeding Tube}

Table 29: Change in requirement of feeding tube (HNFE)

\begin{tabular}{|l|l|l|}
\hline \multicolumn{3}{|c|}{ HNFE } \\
\hline & Before & After \\
\hline 0 & 70 & 80 \\
\hline 100 & 30 & 20 \\
\hline Total & 100 & 100 \\
\hline
\end{tabular}

The requirement of the feeding tube was reported to increase after the intervention. (Table 29) (Figure 17)
- Weight Loss

Table 30: Change in weight loss (HNWL)

\begin{tabular}{|l|l|l|}
\hline \multicolumn{3}{|c|}{ HNWL } \\
\hline & Before & After \\
\hline 0 & 10 & 20 \\
\hline 100 & 90 & 80 \\
\hline Total & 100 & 100 \\
\hline
\end{tabular}

Table 30 shows that those having higher scores earlier, either gained or had the same weight after the intervention (Table 30).

\section{- Weight Gain}

Table 31: Change in weight gain (HNWG)

\begin{tabular}{|l|l|l|}
\hline \multicolumn{3}{|c|}{ HNWG } \\
\hline & Before & After \\
\hline 0 & 90 & 90 \\
\hline 100 & 10 & 10 \\
\hline Total & 100 & 100 \\
\hline
\end{tabular}
31).

None of the patients reported any weight gain (Table

\section{Impact of the intervention}

- On the basis of analysis of EORTC QLQ-C30 (Version 3.0)

The dependent samples t-test was performed to assess the impact of the Vitamin $\mathrm{C}$ intervention. The normally distributed difference scores were examined prior to conducting analysis. The assumption was considered satisfied, as the skew and kurtosis levels estimated were less than the maximum allowable values for a t-test (i.e. skew $<|2.0|$ and kurtosis <|9.0|; Posten, 1984). The summary of the tests performed on the scores of each scale is presented in Table 32 below.

Table 32: Results of dependent samples t-test among EORTC QLQ-C30 (Version 3.0) scale scores

\begin{tabular}{|ll|l|l|l|l|l|}
\hline Scale(s) & $\begin{array}{l}\text { Mea } \\
\text { n }\end{array}$ & SD & t & df & $\begin{array}{l}\text { Sig. } \\
\mathbf{( 2 -} \\
\text { tailed) }\end{array}$ \\
\hline $\begin{array}{l}\text { QL_Before } \\
\text { QL_After }\end{array}$ & - & 10.00 & 41.68 & 1.07 & 19 & 0.3 \\
\hline $\begin{array}{l}\text { PF_Before } \\
\text { PF_After }\end{array}$ & - & -2.33 & 14.87 & -0.7 & 19 & 0.49 \\
\hline $\begin{array}{l}\text { RF_Before } \\
\text { RF_After }\end{array}$ & - & 6.66 & 22.55 & 1.32 & 19 & 0.2 \\
\hline $\begin{array}{l}\text { EF_Before } \\
\text { EF_After }\end{array}$ & 1.66 & 17.23 & 0.43 & 19 & 0.67 \\
\hline $\begin{array}{l}\text { CF_Before } \\
\text { CF_After }\end{array}$ & -1.67 & 24.12 & -0.3 & 19 & 0.76 \\
\hline $\begin{array}{l}\text { SF_Before } \\
\text { SF_After }\end{array}$ & 0.84 & 21.26 & 0.18 & 19 & 0.86 \\
\hline
\end{tabular}




\begin{tabular}{|ll|l|l|l|l|l|}
\hline $\begin{array}{l}\text { FA_Before } \\
\text { FA_After }\end{array}$ & 3.91 & 24.78 & 0.7 & 19 & 0.49 \\
\hline $\begin{array}{l}\text { NV_Before } \\
\text { NV_After }\end{array}$ & -5.00 & 25.98 & -0.9 & 19 & 0.4 \\
\hline $\begin{array}{l}\text { PA_Before } \\
\text { PA_After }\end{array}$ & -5.01 & 23.63 & -0.9 & 19 & 0.36 \\
\hline $\begin{array}{l}\text { DY_Before } \\
\text { DY_After }\end{array}$ & - & 0.01 & 34.20 & 0 & 19 & 1 \\
\hline $\begin{array}{l}\text { SL_Before } \\
\text { SL_After }\end{array}$ & 0.01 & 26.50 & 0 & 19 & 1 \\
\hline $\begin{array}{l}\text { AP_Before - } \\
\text { AP_After }\end{array}$ & 3.35 & 37.31 & 0.4 & 19 & 0.69 \\
\hline $\begin{array}{l}\text { CO_Before } \\
\text { CO_After }\end{array}$ & 16.69 & 27.57 & 2.71 & 19 & $0.01 *$ \\
\hline DI_Before - DI_After & -1.82 & 29.50 & -0.3 & 19 & 0.79 \\
\hline FI_Before - FI_After & -1.65 & 27.51 & -0.3 & 19 & 0.79 \\
\hline
\end{tabular}

To test the hypothesis that the pre Vitamin $\mathrm{C}$ intervention and post Vitamin $\mathrm{C}$ intervention scores for the scales of the questionnaire were equal, a dependent samples t-test was performed. The null hypothesis of no change in the scale's means was accepted for all scales except Constipation $(\mathrm{CO})$ wherein $t_{(19)}=2.71, p<0.05$.

- On the basis of analysis of EORTC QLQ-HN35 (Version 1.0)

The dependent samples t-test was performed to assess the impact of the Vitamin $\mathrm{C}$ intervention. Prior to the the analysis, the assumptions of normally distributed difference scores were examined. The assumption was considered satisfied, as the skew and kurtosis levels estimated were less than the maximum allowable values for a t-test (i.e. skew $<|2.0|$ and kurtosis <|9.0|; Posten, 1984). The summary of the tests performed on the scores of each scale is presented in Table 33 below.

Table 33: Results of dependent samples t-test among EORTC QLQ-HN35 (Version 1.0) scale scores

\begin{tabular}{|ll|l|l|l|l|l|}
\hline Scale(s) & $\begin{array}{l}\text { Mea } \\
\mathbf{n}\end{array}$ & SD & t & df & $\begin{array}{l}\text { Sig. } \\
\text { (2- } \\
\text { tailed) }\end{array}$ \\
\hline $\begin{array}{l}\text { HNPA_Before } \\
\text { HNPA_After }\end{array}$ & -1.25 & 14.6 & -0.38 & 19 & 0.707 \\
\hline $\begin{array}{l}\text { HNSW_Before - } \\
\text { HNSW_After }\end{array}$ & -1.25 & 19 & -0.29 & 19 & 0.772 \\
\hline $\begin{array}{l}\text { HNSE_Before - } \\
\text { HNSE_After }\end{array}$ & -8.33 & 19.1 & -1.95 & 19 & 0.066 \\
\hline $\begin{array}{l}\text { HNSP_Before } \\
\text { HNSP_After }\end{array}$ & -4.44 & 12.7 & -1.57 & 19 & 0.134 \\
\hline $\begin{array}{l}\text { HNSO_Before - } \\
\text { HNSO_After }\end{array}$ & 0 & 13 & 0 & 19 & 1 \\
\hline $\begin{array}{l}\text { HNSC_Before - } \\
\text { HNSC_After }\end{array}$ & 0.667 & 14 & 0.21 & 19 & 0.834 \\
\hline $\begin{array}{l}\text { HNSX_Before - } \\
\text { HNSX_After }\end{array}$ & -5.83 & 20.4 & -1.28 & 19 & 0.217 \\
\hline $\begin{array}{l}\text { HNTE_ Before- } \\
\text { HNTE_After }\end{array}$ & -8.33 & 14.8 & -2.52 & 19 & $0.021^{*}$ \\
\hline
\end{tabular}

\begin{tabular}{|ll|l|l|l|l|l|}
\hline $\begin{array}{l}\text { HNOM_Before - } \\
\text { HNOM_After }\end{array}$ & 1.667 & 25.3 & 0.29 & 19 & 0.772 \\
\hline $\begin{array}{l}\text { HNDR_Before - } \\
\text { HNDR_After }\end{array}$ & -6.67 & 20.5 & -1.45 & 19 & 0.163 \\
\hline $\begin{array}{l}\text { HNSS_Before - } \\
\text { HNSS_After }\end{array}$ & 6.667 & 27.8 & 1.07 & 19 & 0.297 \\
\hline $\begin{array}{l}\text { HNCO_Before - } \\
\text { HNCO_After }\end{array}$ & -8.33 & 23.9 & -1.56 & 19 & 0.135 \\
\hline $\begin{array}{l}\text { HNFI_Before- } \\
\text { HNFI_After }\end{array}$ & -6.67 & 25.6 & -1.16 & 19 & 0.258 \\
\hline $\begin{array}{l}\text { HNPK_Before - } \\
\text { HNPK_After }\end{array}$ & 0 & 45.9 & 0 & 19 & 1 \\
\hline $\begin{array}{l}\text { HNNU_Before - } \\
\text { HNNU_After }\end{array}$ & 0 & 45.9 & 0 & 19 & 1 \\
\hline $\begin{array}{l}\text { HNFE_Before } \\
\text { HNFE_After }\end{array}$ & 10 & 44.7 & 1 & 19 & 0.33 \\
\hline $\begin{array}{l}\text { HNWL_Before } \\
\text { HNWL_After }\end{array}$ & 10 & 30.8 & 1.45 & 19 & 0.163 \\
\hline $\begin{array}{l}\text { HNWG_Before } \\
\text { HNWG_After }\end{array}$ & -10 & 55.3 & -0.81 & 19 & 0.428 \\
\hline
\end{tabular}

To test the hypothesis that the pre Vitamin $\mathrm{C}$ intervention and post Vitamin $\mathrm{C}$ intervention scores for the scales of the questionnaire were equal, a dependent samples t-test was performed. The null hypothesis of no change in the scale's means was rejected for the scale Teeth (HNTE) $t_{(19)}=-2.52, p<0.05$.

\section{Discussion}

Plants and most animals synthesize ascorbic acid using glucose. Humans, however, don't synthesize this compound because the L-gulonolactone oxidase gene doesn't function, and thus this vitamin is obtained through the diet as ascorbate and dehydroascorbic acid (DHA). Vitamin $\mathrm{C}$ has been proven to be an anti oxidant helpful in treatment and/or prevention and mitigation of Cancer through various clinical and non clinical studies. (Mata, Carvalho, Alencar, Carvalho Melo CavalCante, \& da silva, 2016)

Patients in the Mayo Clinic trials received oral ascorbate (Vitamin C). Some years later, clinical data were generated that demonstrated that when ascorbate is given orally, plasma concentrations are tightly controlled. At oral doses of $200 \mathrm{mg}$, the steady-state plasma concentrations are $\approx 80 \mu \mathrm{M}$. As doses exceed $200 \mathrm{mg}$, relative absorption decreases, urine excretion increases and therefore the fraction of bioavailable ascorbate is reduced. Peak plasma values don't exceed $\approx 220 \mu \mathrm{M}$ even after maximum oral dose of three g 6 times daily (Levine M, 1996).

Many studies have demonstrated that cancer patients experience vitamin $\mathrm{C}$ deficiency correlated with reduced oral intake, inflammation, infection, disease processes, and treatments such as radiation, chemotherapy, and Many studies have demonstrated that cancer patients experience vitamin $\mathrm{C}$ deficiency correlated with reduced oral intake, inflammation, infection, disease processes, and coverings 
like radiation, chemotherapy, and surgery. (Yeom $\mathrm{CH}$, 2007) (FA., 1985) (Mayland CR, 2005.) (Fain O, 2003) (S., 2003) Studies report reductions in inflammatory markers and suggest some improvement in symptoms, with a possible benefit in quality of life (qol) when IV $\mathrm{C}$ alone or together with oral vitamin $\mathrm{C}$ is employed in oncologic care. (Romney SL, 1987)(Jonas CR, 2000).

Klimant et.al proposed a practical approach for the administration of IV and oral vitamin $\mathrm{C}$ as a supportive therapy, including recommendations to make sure safety before and after chemotherapy. (Klimant E., Wright, Rubin, Seely, \& Markman, 2018). Many studies have described that intravenous ascorbic acid is more effective for raising serum levels of ascorbate than the form administered orally (Mandl J, 2009)The present study concludes that the oral intake of Vitamin $\mathrm{C}$ is beneficial for cancer patients but is not significantly effective. As suggested by recent studies mentioned earlier, the administration of the vitamin should be done along with the other effective supplements including Intravenous Vitamin C.

\section{Conclusion}

The impact of consumption of $120 \mathrm{mg} /$ day Vitamin C through natural resources (fruits and vegetables) on the quality of life was assessed and evaluated by EORTC QLQ-C30 (Version 3.0) and EORTC QLQ-HN35 (Version 1.0). 20 patients diagnosed with Head and Neck cancer having varied disease stage and treatment modality were selected and were administered both the questionnaires twice- before and after the Vitamin $\mathrm{C}$ intervention. For assessing the impact of the intervention on the quality of life of the patients the dependent sample $t$ test was performed. The result of this statistical treatment suggest that the intervention has proved to give significant improvement of constipation in the general quality of life and in the teeth related troubles of the head and neck cancer patients in particular. Therefore the study concludes that the intake of Vitamin $\mathrm{C}$ from the natural sources (i.e. fruits and vegetables) is beneficial to the Cancer patients in general and Head and neck cancer patients in particular.

\section{Recommendations}

Recommendations for further study are,

- Impact of intravenous administration of Vitamin $\mathrm{C}$ on quality of life should be assessed

- Other cancer sites can also be examined

- Standardised, valid and reliable questionnaire should be developed for the examination of dietary intake and requirement of the Indian population.

- Requirement and impact of other micronutrients on the well being of the cancer patients should be done.
- Reference values should be compiled for Indian population related to the quality of life of the patients.

\section{Reference}

[1] Aaronson NK, A. S. (1993). The European Organisation for Research and Treatment of Cancer QLQ-C30: A quality-of-life instrument for use in international clinical trials in oncology. . Journal of the National Cancer Institute , 365-376.

[2] Aaronson NK, A. S. (1993). The European Organisation for Research and Treatment of Cancer QLQ-C30: A quality-of-life instrument for use in international clinical trials in oncology. . Journal of the National Cancer Institute , 365-376.

[3] Cloos PA, C. J. (2008). Erasing the methyl mark: histone demethylases at the center of cellular differentiation and disease. Genes Dev, 1115-1140.

[4] Dua, J., Cullena, J. J., \& Buethnera, G. R. (2012). Ascorbic acid: Chemistry, biology and the treatment of cancer. Biochim Biophys Acta , 443-457.

[5] FA., H. (1985). Micronutrient requirements of cancer patients. Cancer , 295-300.

[6] Fain O, P. J. (2003). Hypovitaminosis C in hospitalized patients. Eur J Intern Med . , ;419-25.

[7] Fayers PM, A. N. (2001). The EORTC QLQ-C30 Scoring Manual (3rd Edition). . Brussels: European Organisation for Research and Treatment of Cancer.

[8] Jonas CR, P. A. (2000). Plasma antioxidant status after high-dose chemotherapy: a randomized trial of parenteral nutrition in bone marrow transplantation patients. Am J Clin Nutr , 181-90.

[9] Ki, B., \& Mead, M. N. (2003). Vitamin C in alternative cancer treatment: historical background. Inteqr Cancer Ther, 147-54.

[10] Klimant, E., Wright, H., Rubin, D., Seely, D., \& Markman, M. (2018). Intravenous vitamin $C$ in the supportive care of cancer patients:a review and rational approach. Current Oncology, 139-148.

[11] Klimant, E., Wright, H., Rubin, D., Seely, D., \& Markman, M. (2018). Intravenous vitamin $C$ in the supportive care of cancer patients:a review and rational approach.Current Oncology , 139-148.

[12] Levine M, C.-C. C. (1996). Vitamin C pharmacokinetics in healthy volunteers: evidence for a recommended dietary allowance. Proc Natl Acad Sci U S A , 3704-3709.

[13] Lu H, D. C. (2005). Reversible inactivation of HIF-1 prolyl hydroxylases allows cell metabolism to control basal HIF-1. J Biol Chem , 41928-41939.

[14] Mandl J, S. A. (2009). Vitamin C: update on physiology and pharmacology. Br J Pharmacol. , 1097-110.

[15] Mata, A. d., Carvalho, R. d., Alencar, M. d., Carvalho Melo CavalCante, A. d., \& da silva, B. B. (2016). Ascorbic acid in the prevention and treatment of cancer. Rev Assoc Med Bras , 680-686.

[16] Mayland CR, B. M. (2005.). Vitamin C deficiency in cancer patients. Palliat Med , 17-20.

[17] Ohno, S., Chno, Y., Suzuki, N., Soma, G.-I., \& Inoue, M. (2009). High-dose Vitamin C (Ascorbic Acid) Therapy in the Treatment of Patients with Advanced Cancer. International journal of Cancer research and treatment, 809-815.

[18] Park, S. (2013, September 9). The Effects of High Concentrations of Vitamin C on Cancer Cells. Nutrients , 3496-3505.

[19] Romney SL, B. J. (1987;.). Plasma reduced and total ascorbic acid in human uterine cervix dysplasia and cancer.Ann NY Acad Sci, 13243.

[20] S., M. (2003). Antioxidant nutrients and chronic disease: use of biomarkers of exposure and oxidative stress status in epidemiologic research. J Nutr, 933S-40S.

[21] Wilson, M. K., Baguley, B. C., Wall, C., Jameson, M. B., \& Findlay, M. P. (2014). Review of high-dose intravenous vitamin $C$ as an anticancer agent. Asia-Pacific Journal of Clinical Oncology , 22-37.

[22] Yeom CH, J. G. (2007). Changes of terminal cancer patients' healthrelated quality of life after high dose vitamin $\mathrm{C}$ administration. $\mathrm{J}$ Korean Med Sci . , 7-11. 